

\section{Territorio, paisaje y valores patrimoniales en Úbeda y Baeza}

Ana Coronado Sánchez, arquitecta

\section{COMPRENSIÓN-REPRESENTACIÓN COMPARTIDA}

Úbeda y Baeza pertenecen al mismo espacio geográfico, la comarca de La Loma, que define el escenario en el que se representan las dos ciudades. Un territorio moldeado por las lomas y peinado por los olivos se acomoda sobre la plataforma de su cornisa central entre los valles del Guadalquivir y el Guadiana. Esta posición de control territorial y de balcón hacia Sierra Mágina (hacia el sur) explica y determina el sistema de asentamientos y el paralelismo morfológico de ambas ciudades.

La Loma es el ámbito territorial de encuentro entre los suaves cerros de Sierra Morena y las agrestes estribaciones del sistema bético, cruzado por el valle del Guadalquivir. Los tres espacios territoriales más extensos de Andalucia se anudan en este corredor, haciendo perceptible su diversidad.

Otro de los elementos fundamentales para entender el papel territorial de Úbeda y Baeza en el sistema de asentamientos de La Loma es su condición histórica de rótula territorial conectando el valle del Guadalquivir con el Levante y Sierra Morena con la submeseta sur. Su carácter de cruce de caminos ha aportado la posición de centros territoriales a Úbeda y Baeza hasta que, en siglo XVIII, las políticas de articulación territorial dejaron fuera del vector de desarrollo a la comarca de La Loma. A partir del siglo XIX, la formación de una burguesía comercial fundamentalmente en Úbeda hizo que se convirtiera en el centro territorial de la comarca.

Úbeda y Baeza no pueden entenderse como hechos urbanos aislados cultural, ni patrimonial, ni paisajisticamente ya que forman parte de un sistema dual de relaciones, incidencias y representaciones compartidas sobre el territorio a pesar de que sus políticas urbanisticas a lo largo del siglo XX no hayan respondido a esta lógica.

El entendimiento de Úbeda y Baeza como una realidad territorial compartida ha sido reflejado en múltiples miradas, desde la de
Wyngaerde hasta la de Antonio Machado o más recientemente la de Antonio Muñoz Molina. Pero sobre todo desde la conciencia colectiva de sus habitantes a través del reconocimiento común en ese paisaje y enclave dual del Renacimiento.

Los planteamientos patrimoniales convencionales han tendido a separar las cuestiones territoriales de los valores urbanos o arquitectónicos, estableciendo clasificaciones descontextualizadas con mecanismos de protección sobre los bienes urbanos pero descuidando los aspectos territoriales y paisajisticos. Esto explica la contradicción evidente entre los valores patrimoniales otorgados al territorio intermedio de Úbeda y Baeza y su destrucción por la falta de una planificación que clarifique y establezca estrategias y objetivos entre las distintas administraciones locales y sectoriales que operan sobre él.
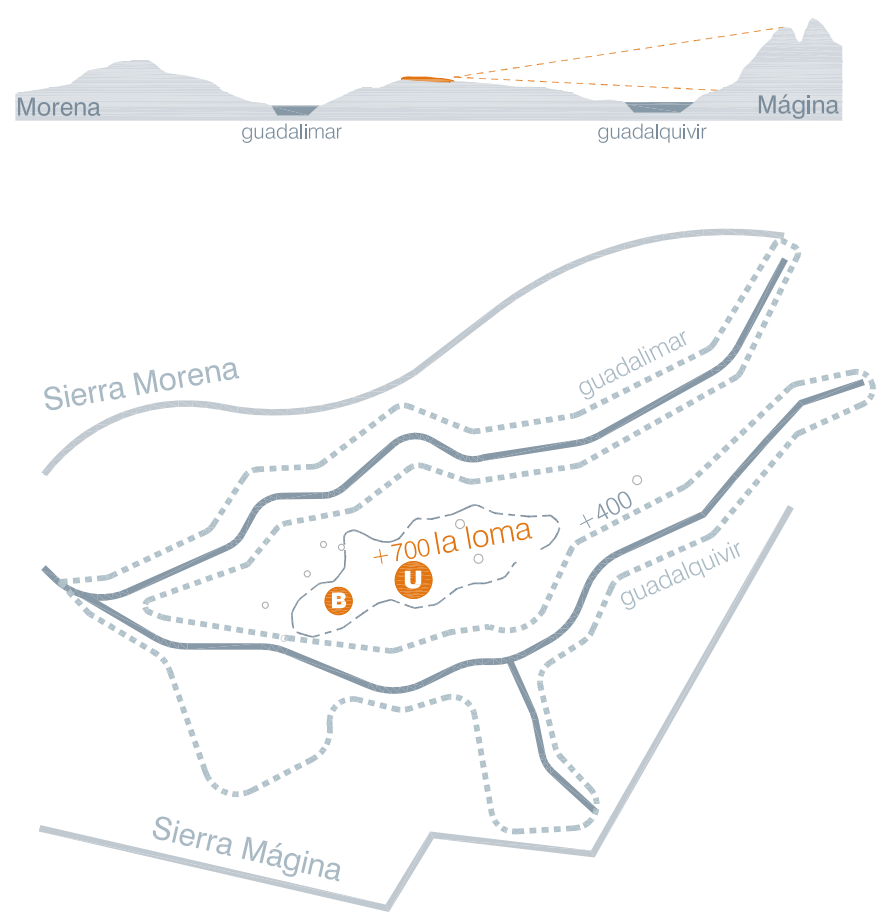

Diagramas territoriales de La Loma. Fuente: Elaboración propia 


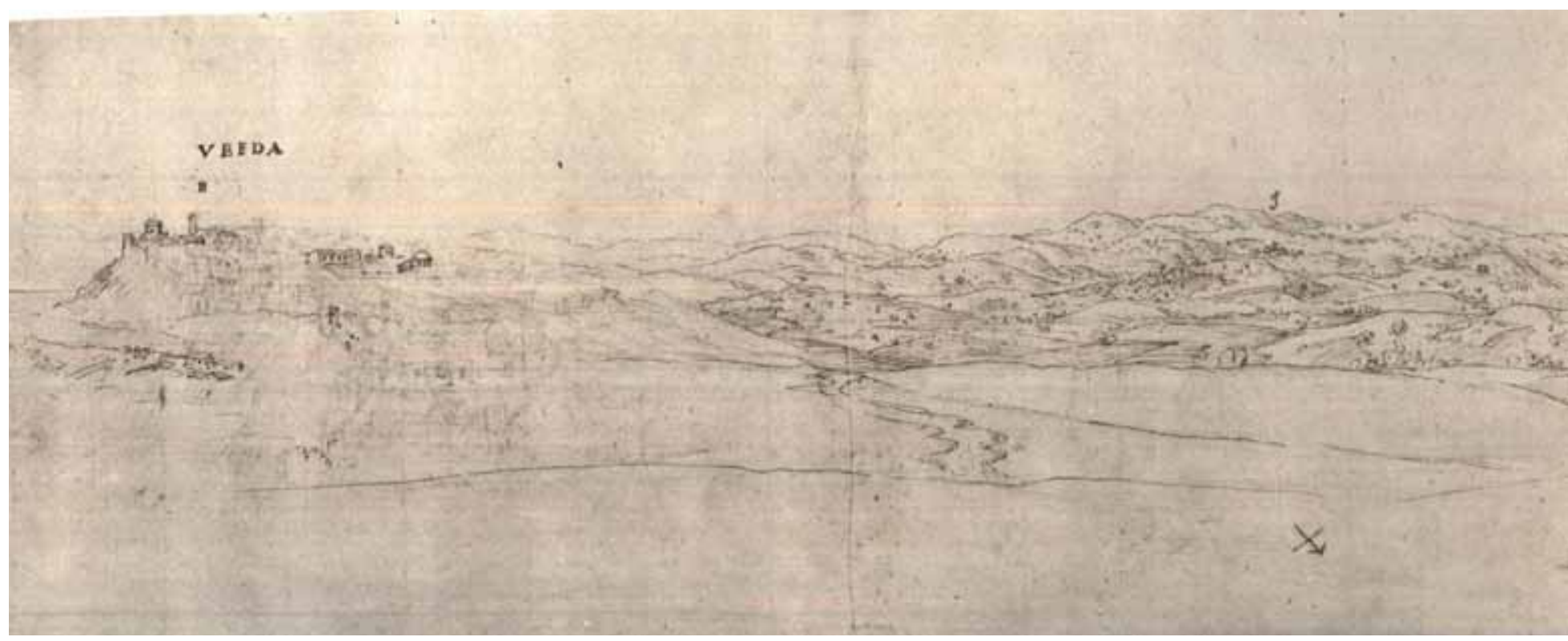

Dibujo de Anton Van den Wyngaerde, s. XVI. Fuente: GALERA ANDREU, 2003: 17

\section{PAPELES DEL TERRITORIO. CONSTRUCCIÓN DEL PAISAJE}

El territorio de La Loma, debido a su condición de punto de enlace entre corredores de comunicación, a sus características topográficas y a la potencialidad de sus recursos, ha sido un territorio habitado desde épocas muy tempranas y, por lo tanto, en constante transformación. Su paisaje es el patrimonio que nos muestra hoy la forma en la que los habitantes de La Loma han modificado y moldeando su entorno en su progresivo habitar a través de las respuestas que han ido dando ante las dificultades y ante los recursos elaborando progresivamente una cultura territorial singular y específica.

\section{Enclaves}

En el Paleolítico aparecen comunidades humanas que se van asentando en las terrazas de los valles. En el Neolítico se inicia un proceso de sendentarización debido a un incipiente desarrollo de la agricultura y de la ganadería, lo que supone una organización territorial muy temprana que utiliza el eje norte-sur a modo de corredor de comunicaciones, ya que es la vía natural de penetración desde el valle del Guadalquivir. En este sistema de asentamientos, predominan aquellos que aprovechan las condiciones de fertilidad que ofrece la vega aproximándose a la desembocadura del Guadalquivir, aunque se ocupan también las zonas más estables y altas de la meseta y las cotas intermedias, a caballo entre la meseta y la vega.

\section{Ruta. Época romana}

En esta época se establece un nuevo orden territorial debido al enlace con la ruta comercial que contectaba con Cástulo y permitía la salida de la plata desde las minas de Sierra Morena hacia
Roma. Baeza y Úbeda la Vieja o la Ciudad Salaria se constituyen como principales centros económicos de la comarca, abandonando gran cantidad de poblados y concentrándose progresivamente en los principales núcleos.

\section{Encrucijada. Islam}

En las invasiones hispano godas este territorio había perdido el poder económico y se habia producido un éxodo desde los núcleos de población hacia el campo. Durante el siglo IX, la política de articulación estatal del mundo islámico impulsa la consolidación de Úbeda y Baeza como ciudades centrales, configurando su estructura urbana mediante una doble estrategia: el control del valle del Guadalquivir y la puesta en carga del territorio introduciendo nuevas técnicas productivas mediante huertas en las faldas sur y suroeste de Úbeda y Baeza respectivamente. A medida que los ataques cristianos son más frecuentes se produce una mayor concentración y fortificación, abandonando en gran medida el medio rural.

\section{Frontera}

La conquista cristiana de Úbeda y Baeza, en 1233 y 1226 respectivamente, atribuye la condición de frontera a la cornisa central de La Loma, utilizándose como plataforma para nuevas conquistas en el avance hacia el reino de Granada. Dominar este territorio es crucial en el esquema geoestratégico del reino cristiano, por lo que a través del Fuero de Cuenca se pretende generar una oligarquia social mediante un sistema de privilegios y títulos nobiliarios. Esto generará el caldo de cultivo necesario para los desarrollos y avances de los siglos posteriores, en los que Úbeda y Baeza alcanzarán su máximo protagonismo. 


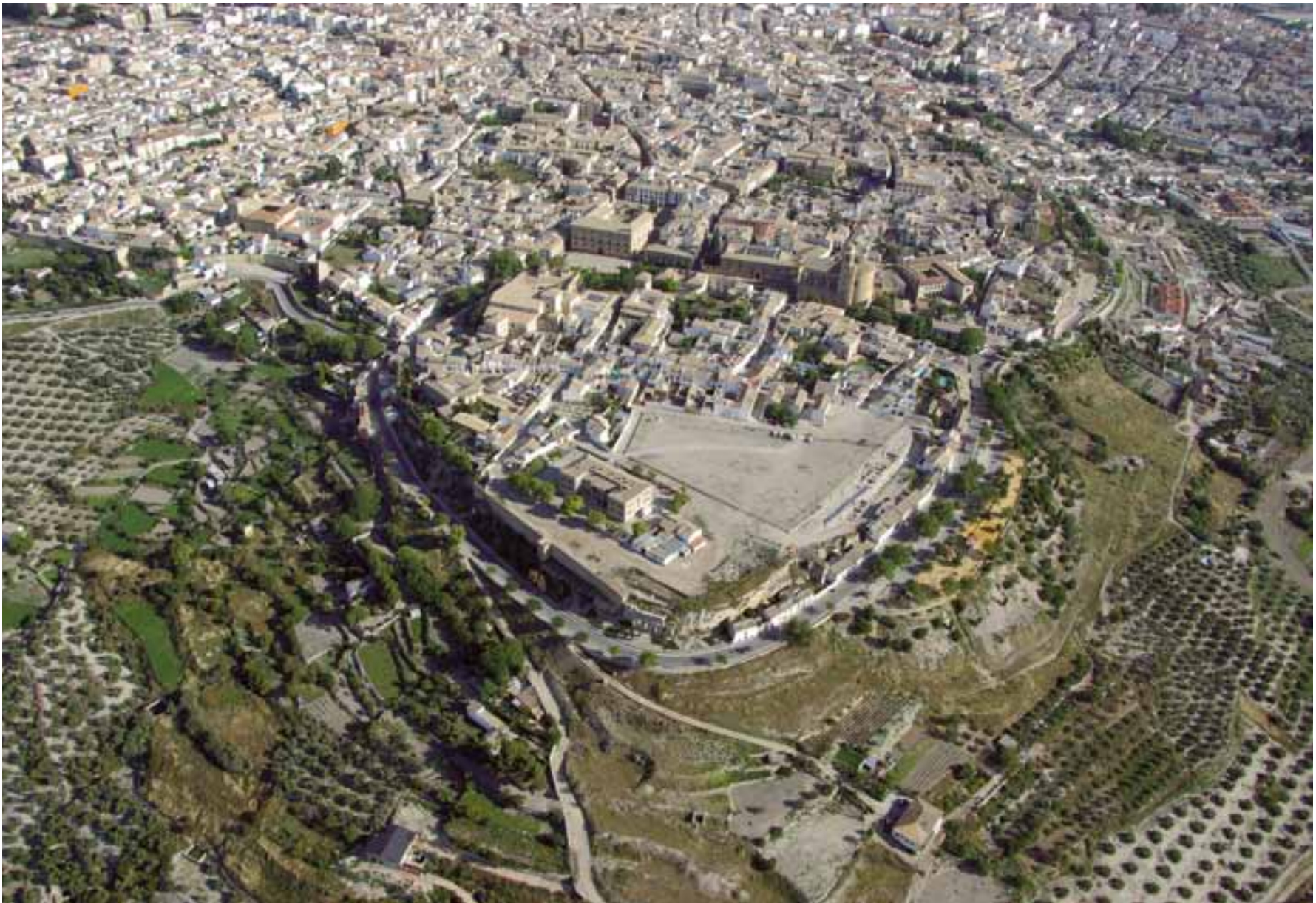

Vista aérea de Úbeda. Foto: José Carlos Sánchez Ruiz

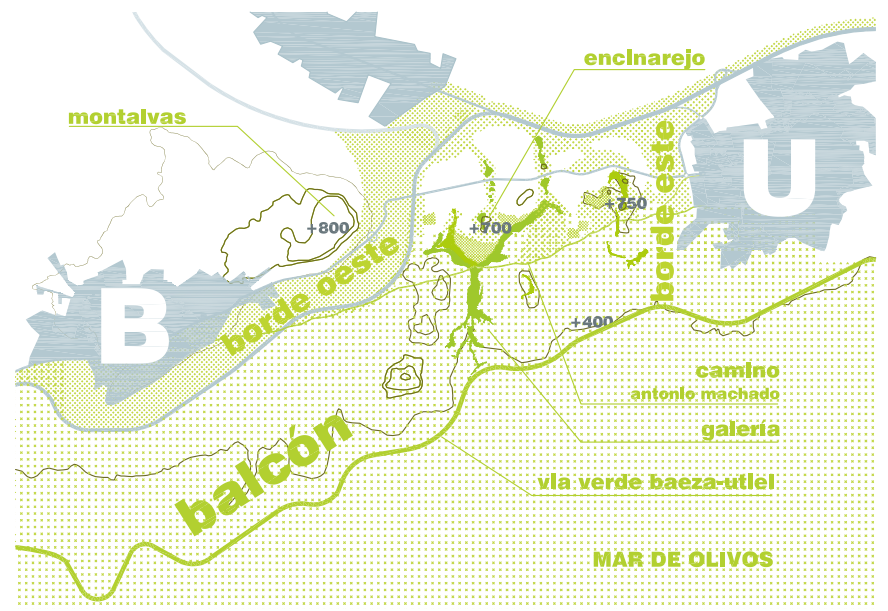

Diagrama de corredores y singularidades paisajísticas. Fuente: Elaboración propia

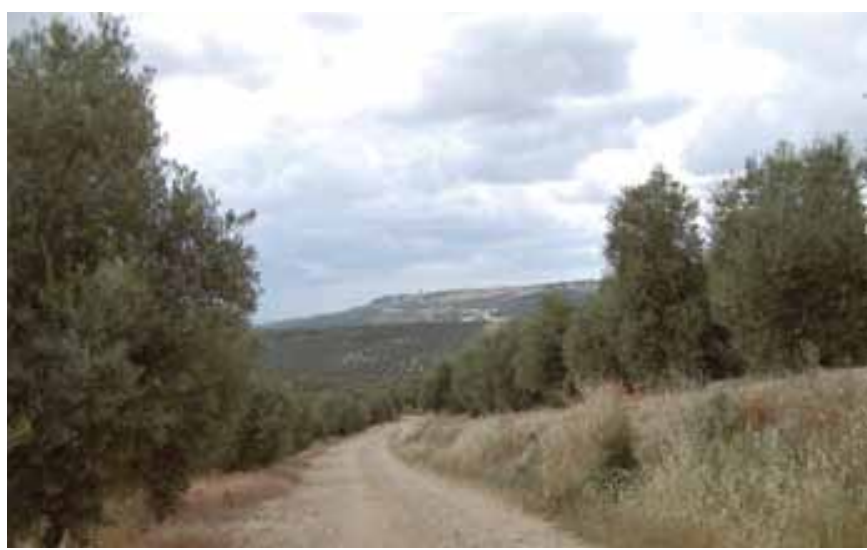

Entorno de las ciudades de Úbeda y Baeza visto desde el sur. Foto: Ana Coronado

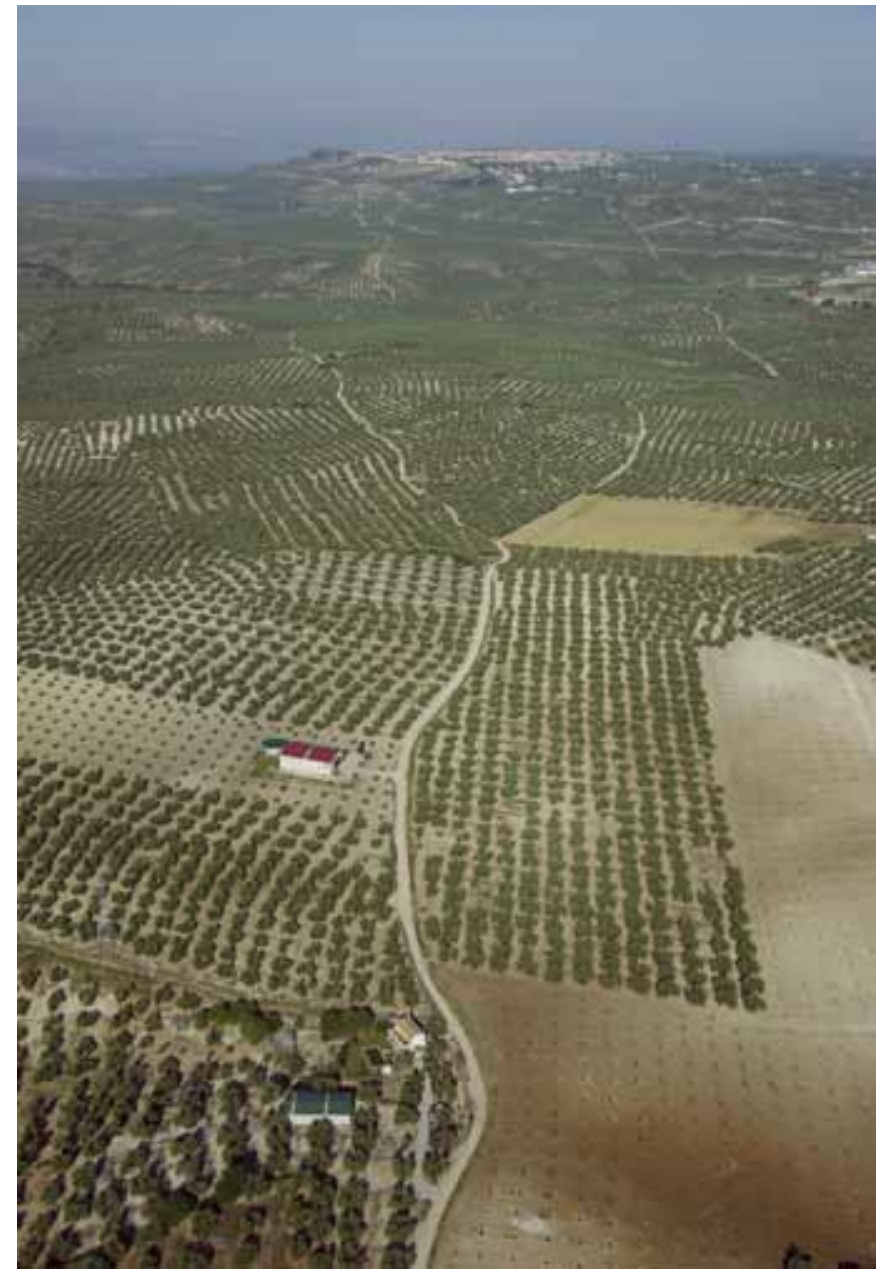

Camino de Antonio Machado. Foto: José Carlos Sánchez Ruiz 
El territorio entre Úbeda y Baeza es un espacio amenazado. Ante un territorio industrializado, altamente accesible, progresivamente ocupado con programas no cualificados y con distancias mínimas entre las ciudades, el fracaso histórico de los procesos de urbanización y construcción nos conduce a la necesidad de cambiar de estrategia. Lo relevante en esta nueva estrategia es priorizar la protección activa de corredores y lomas que singularizan su paisaje, recuperando el significado de balcón territorial mediante el reciclaje de los espacios ya degradados, frente a un crecimiento que ocupa progresivamente nuevos suelos.

Para ello es necesario romper la dialéctica centro-periferia no estableciendo relaciones de dependencia y concibiendo ese espacio intermedio no como periferia de una y otra ciudad, sino como puerta territorial de La Loma. Esto requiere desarrollar una política que integre las inversiones públicas en materia de infraestructuras y nuevos programas generando valores añadidos a partir de su integración paisajística. En segundo lugar, es necesario superar su carácter exclusivamente productivo para implementar una diversidad funcional que aproveche la oportunidad de ubicar y conectar equipamientos y servicios territoriales que otorguen nuevos valores a este espacio.

A través de la frase "Renacimiento que mira al mar" (de olivos) se resume lo que es fundamental para entender uno de los valores más interesantes desde el punto de vista territorial de Úbeda y Baeza; la condición predominante y dual de dos ciudades que "miran" al valle del Guadalquivir a través de cerros y lomas con la profundidad del background de Sierra Mágina.

Los cerros de las dos ciudades que emergen como dos de los elementos más altos del balcón se sitúan en torno a las cotas 750 . Estos son "cosidos" a su vez por cadenas de cerros más pequeños entre los que discurren a través de sus vaguadas los arroyos que irán a desembocar al río y que se encuentran protegidos por algunos restos de bosques galería que ofrecen espacios de singularidad. Las cadenas de cerros se enlazan en la plataforma centra que adquiere una mayor potencia por el corte brusco producido alrededor de la cota +650 , dando pie posteriormente a una bajada mucho más suave hasta el río Guadalquivir.

En las faldas hacia el sur de las ciudades aún se conservan, aunque amenazados por los procesos urbanizadores, los huertos que tras los paseos amurallados de ambas ciudades generan la transición de la ciudad al campo y otorgan una imagen singular en el primer plano de la escena paisajística.

El cerro de las Montalvas, al noreste de Baeza, es el punto más alto, situándose en la cota $800 \mathrm{~m}$. Domina visualmente todo el territorio y a su vez presenta una imagen rotunda y autónoma en las perspectivas de Úbeda, de Baeza y de toda la cornisa central. Se trata del espacio más sensible paisajísticamente por sus dimensiones y su alta visibilidad. Sin embargo, por su condición periférica desde el punto de vista del crecimiento de Baeza, se ocupa progresivamente sin una ordenación que cualifique su paisaje.
El camino de Antonio Machado (San Antonio como nombre popular), habiendo dejado de jugar un papel funcional en la comunicación de las ciudades, ofrece múltiples puntos de observación al recorrer transversalmente el espacio intermedio en el sentido este-oeste. Incorpora vestigios del pasado y flores silvestres que han tenido la oportunidad de florecer, ajenas al tránsito de los coches. Desde este camino, se dan cabida el polvo y la aridez de lo cercano y también la apertura del valle y el fondo de perspectiva de Sierra Mágina.

\section{।}

Desde mi ventana, ¡campo de Baeza, a la luna clara! ¡Montes de Cazorla, Aznaitín y Mágina!

¡De luna y de piedra también los cachorros de Sierra Morena!

II

Sobre el olivar, se vio la lechuza volar y volar. Campo, campo, campo.

Entre los olivos,

los cortijos blancos.

Y la encina negra,

a medio camino

de Úbeda a Baeza.

$(\ldots)^{2}$

El camino es un espacio singular que se mantiene tal y como Machado lo recorría. Conecta con el Encinarejo, lugar que se encuentra en la mitad del trayecto en el que se sentaba bajo las copas de sus encinas, que prestaban sombra, frescura y un techo vegetal que marcaba la perspectiva y hacia posible encuadrar el paisaje.

En la cota 400 se encuentra la antigua vía de ferrocarril Baeza-Utiel, nunca inaugurada, que se incorporó a este paisaje, ofreciendo un recorrido este-oeste con sus túneles y estaciones abandonados. Aquellas viejas vías y puentes del ferrocarril Baeza-Utiel son la evidencia de la decadencia que da como resultado un territorio desconectado, que ofrece, asimismo, la oportunidad de ser rescatado como elemento generador de nuevos usos ambientales.

Estos lugares singulares configuran la estructura paisajistica del entorno. La protección entendida convencionalmente no ha ofrecido garantías para su preservación, quizá sólo es posible desde un entendimiento más amplio que conecte con la misma lógica que lo generó, el mantenimiento y disfrute de su actividad ligada a la población pero dotándolos de nuevos sentidos imaginativos. 


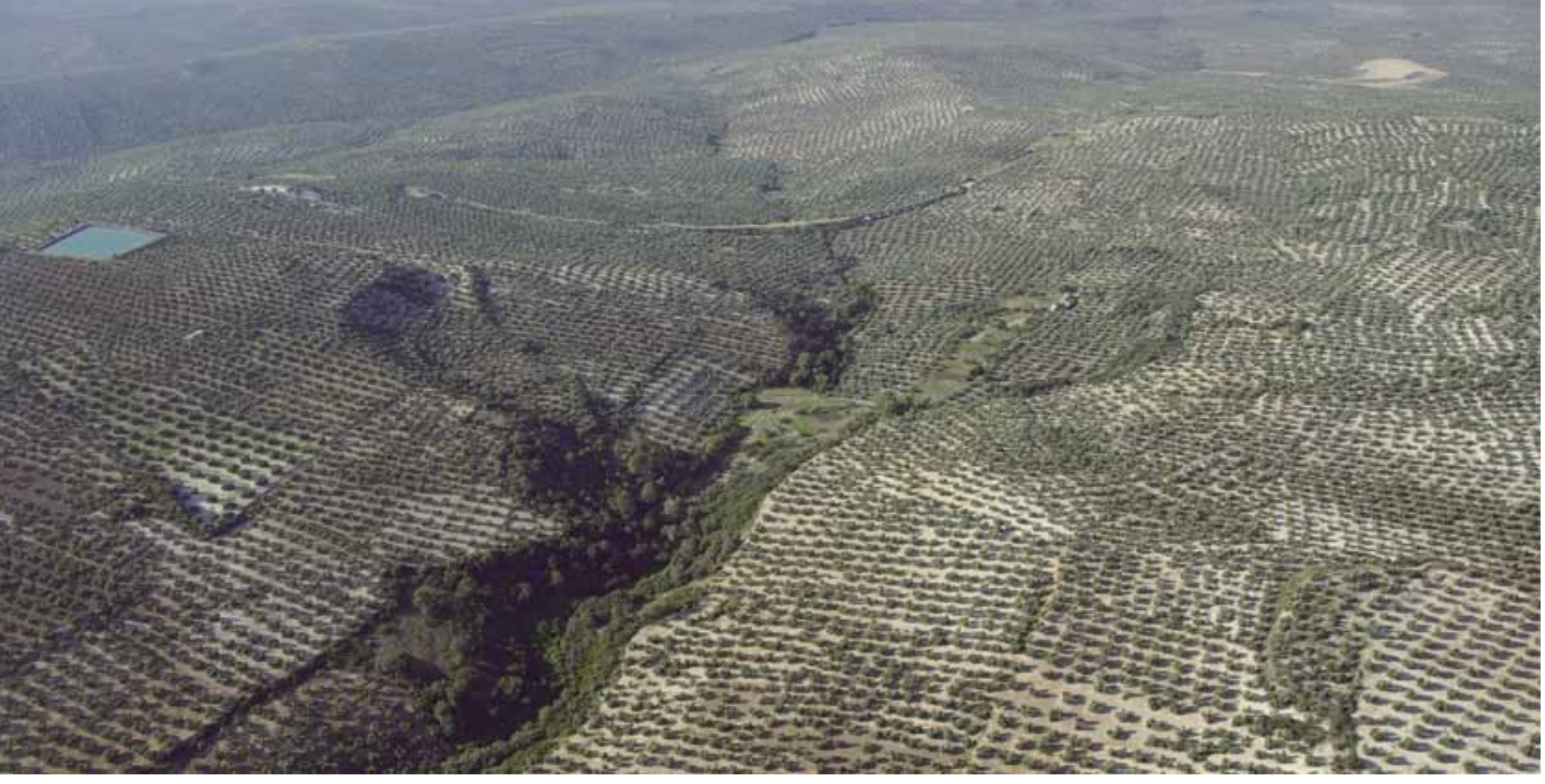

Camino de Antonio Machado. Foto: José Carlos Sánchez Ruiz

El rescate de los espacios degradados, la recuperación de la diversidad ambiental y la puesta en valor de las singularidades paisajisticas a través de la generación de corredores territoriales que preserven y activen los lugares más frágiles, como los cerros, las vaguadas de bosques galería o los huertos, serian estrategias de protección activa que permitirian reestablecer un sentido paisajistico al tiempo que hacerlos accesibles, evitando que el espacio central entre ambas ciudades devenga en un continuo edificado ante la permanente amenaza de su posición estratégica y la ineficacia de las medidas proteccionistas convencionales.

La puesta en valor de estos espacios como articuladores del territorio, junto con la construcción del nuevo programa territorial compartido y la integración de las nuevas infraestructuras, ofreceria la oportunidad de generar un frente hacia el paisaje plurifuncional y equipado, a modo de "paseo marítimo" hacia el "mar de olivos". Se daría así continuidad a los itinerarios turisticos de las dos ciudades y promoveria una experiencia paisajística diversa desde lo urbano hasta el río Guadalquivir pasando por la antigua vía de ferrocarril Baeza-Utiel y por la perspectiva intermedia del camino de Antonio Machado.

\section{Notas}

1 PLAN, 2006.

${ }^{2}$ Fragmento poema Apuntes de Antonio Machado añadido a la $2^{\circ}$ edición de Campos de Castilla (1917).

\section{Bibliografía}

CORONADO SÁNCHEZ, A. (2009) Face to face. Estrategias territoriales en la cornisa central de la loma. Proyecto final de carrera de la ETS de Arquitectura de Sevilla. Universidad de Sevilla, 2009, inédito
DELGADO BUJALANCE, B.; OJEDA RIVERA, J. F. (2007) El viaje pedagógico como método de conocimiento de paisajes. Aplicación a Andalucía. Investigaciones Geográficas. n. ${ }^{\circ} 44,2007$, pp. 1-38

DELGADO BUJALANCE, B.; OJEDA RIVERA, J. F. (2009) La comprensión de los Paisajes Agrarios Españoles. Aproximación a través de sus representaciones. Boletín de la $A G E$, n. ${ }^{5}$ 51, 2009, pp. 93-126

GALERA ANDREU, P. (2003) Úbeda y Baeza en su entorno: una singular irradiación urbana y arquitectónica. En W. AA. Informe de Justificación de Valores. Conjuntos Monumentales de Úbeda y Baeza. Enclave dual del Renacimiento Español. Sevilla: Consejería de Cultura, Junta de Andalucia, 2003 MÁROUEZ, F. (2004) La Voz Andalucía. Enciclopedia General de Andalucía. Madrid: C\&T, 2004

MARTIGNONI, J. (2008) Latinscape. El paisaje como materia prima. Colección Land\&Scape Series. Barcelona: Gustavo Gili. S.L., 2008

MARTíN. J.; SÁNCHEZ, M. (1994) La Comarca de la Loma. Colección Patrimonio Medioambiental y Humano. Madrid: Fundación Cultural Banesto, 1994 OJEDA, J. F. (2008) Los paisajes como patrimonios naturales, históricos y culturales y factores de desarrollo contemporáneo. Aplicaciones andaluzas. Ponencia del curso Paisaje cultural y turismo. ¿Recurso, producto o merco determinante de la calidad de un destino? Mota del Cuervo, 2008, inédito PLAN de Ordenación del Territorio de Andalucía (2006), Título II, Consejería de Obras Públicas y Vivienda de Andalucia, 2006

RUBIO, F. (2008) La Baeza de Machado. Jaén: Fundación José Manuel Lara, 2008 TARIFA, A. (1999) Historia de Úbeda. Granada: Ayuntamiento de Granada, 1999 ZOIDO NARANJO, F. (2002) Andalucia. Cohesión y Diversidad. Scripta Nova [en linea], v. 6, n. 128,2002 http://www.ub.es/geocrit/sn/sn-128.htm [consulta: 29/03/11]

W. AA. (2004) Ferrocarriles y tranvias en Linares, La Carolina y La Loma. Monografías del Ferrocarril, v. 17. Barcelona: Luis Prieto, 2004

W. AA. (2004) Informe de Justificación de Valores. Conjuntos Monumentales de Úbeda y Baeza. Enclave dual del Renacimiento Español. Sevilla: Consejeria de Cultura de la Junta de Andalucia, 2003 